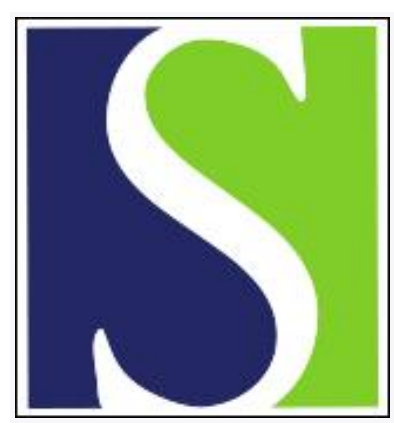

Scand J Work Environ Health 1986;12(4):332-337

https://doi.org/10.5271/sjweh.2134

Issue date: Aug 1986

Handlebar vibration of a motorcycle during operation on different road surfaces.

by Yokomori M, Nakagawa T, Matsumoto T

This article in PubMed: www.ncbi.nlm.nih.gov/pubmed/3775318

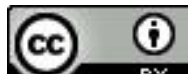




\title{
Handlebar vibration of a motorcycle during operation on different road surfaces
}

\author{
by Motomu Yokomori, PhD, ${ }^{1}$ Takeo Nakagawa, MD, ${ }^{2}$ Tadao Matsumoto, $\mathrm{MD}^{3}$ \\ YOKOMORI M, NAKAGAWA T, MATSUMOTO T. Handlebar vibration of a motorcycle during \\ operation on different road surfaces. Scand $J$ Work Environ Health 12 (1986) 332-337. In Japan daily \\ motorcycle mail deliverers have been exposed to vibration from the handlebars of their motorcycles. \\ Handlebar vibration was measured during the operation of a motorcycle in order to evaluate the hazardous \\ effects of vibration and to identify preventive measures against the vibration hazards. Tests were made \\ on asphalted, unpaved, and packed-snow road surfaces. The tested motorcycles were selected from the \\ many motorcycles in daily use. The test motorcycle was a 1 -cylindered, $89-\mathrm{cm}^{3}$, 4-cycle machine. The \\ direction showing the maximum value of vibration acceleration was not always in the directions of $X$, \\ $\mathrm{Y}$, and $\mathrm{Z}$ proposed by the International Organization for Standardization (ISO). The maximum vibration \\ acceleration level exceeded the exposure guideline of ISO, while its frequency corresponded to that of \\ the engine speed during operation. Vibration of $>20 \mathrm{~Hz}$ was transmitted through the front forks from \\ the road surface and tires.
}

Key terms: acceleration level, engine, exposure guideline, frequency, mail deliverers, tire, unsprung mass, vibration hazards, vibration level.

In Japan motorcycles are widely used for daily postal deliveries and bill collections $(5,6)$. The symptoms caused by vibration hazards are on the increase. In the past, motorcycle vibration was studied to evaluate riding comfort and safety in terms of handling and stability. Reports which refer to this subject are fewer than those which refer to four-wheeled vehicles because the factors which relate to the aforementioned problems are many and complex, and making measurements is difficult while the motorcycle is in motion. Nevertheless, there have been a few studies concerned with the hygiene of the rider $(1,2,7)$.

We have been studying the vibration of motorcycles since 1975 in order to evaluate the hazardous effects of vibration and also to propose measures which will reduce the risk of vibration damage from motorcycles used in postal service for prolonged periods of time (8). The main factors involving vibration hazards of motorcycles are the vibration coming from the motorcycle itself, the posture of the hands and arms during the gripping of the handlebars, the surrounding environment, and the period of time during which the motorcycle is ridden.

1 Transport Machine Engineering, Faculty of Science and Technology, Meijo University, 1-501 Shiogamaguchi, Tempaku-ku, Nagoya 468, Japan.

2 School of Physical Education, Chukyo University, Kaizucho, Toyota, Aichi 470-03, Japan.

3 Department of Public Health, Nagoya City University Medical School, 1 Kawasumi, Mizuho-cho, Mizuho-ku, Nagoya 467, Japan.

Reprint requests to: $\mathrm{Mr}$ M Yokomori, Transport Machine Engineering, Faculty of Science and Technology, Meijo University, 1-501 Shiogamaguchi, Tenpaku-ku, Nagoya 468, Japan.
Vibration is transmitted from the motorcycle along the following three paths: (i) from the handlebars to the hand-arms and the body; (ii) from the saddle to the buttocks, the waist, and the body; and (iii) from the foot rest to the feet, the legs, and the body. The vibration of the handlebars is caused by the engine vibration, the roughness of the road, and the vibration of the frame and the chasis.

The roads for delivering mail have been asphalted in the cities and, usually, in the mountain villages. But there are many unpaved roads still remaining, and, in cold areas, deliveries are made on snow-covered and frozen roads for a rather long period in winter.

In this report, we studied the vibration of the handlebars of a motorcycle moving over level asphalted, unpaved, and packed-snow covered roads. The exposure guidelines of the International Standardization for Organization (ISO) were used for comparison with the results (13).

\section{Tests}

The test motorcycle, which we used for postal deliveries, has a four-stroke, single-cylindered engine with an $89-\mathrm{cm}^{3}$ stroke volume. It was tested on three different road surfaces (asphalt, unpaved surfaces, and packed snow). The asphalt road was smooth and even. The unpaved road was made of packed soil and lcose gravel, and the packed-snow surface consisted of 4-5 $\mathrm{cm}$ of snow, packed on top of about $2 \mathrm{~cm}$ of ice, which covered an asphalted road surface.

The mean vehicle speed was determined from the running time along $100 \mathrm{~m}$ of asphalted and unpaved roads, or $50 \mathrm{~m}$ of snow-covered roads. The selected speeds on the asphalted and unpaved surfaces were 
from 10 to $50 \mathrm{~km} / \mathrm{h}$ in $10 \mathrm{~km} / \mathrm{h}$ intervals for each test. A maximum speed of $30 \mathrm{~km} / \mathrm{h}$ was used on the packed snow because of safety considerations.

Table 1 shows the different front and rear tire combinations used in our tests on packed snow and, except for the test 2 combination, on asphalted roads. The combinations of normal, snow, chained snow, and studded snow tires that we used in this test are generally used in winter by motorcycle riders. In our tests on asphalted and unpaved roads, normal treaded tires were also used.

The vibration acceleration was measured on the iron parts of the handlebar near the left handgrip. The direction of the measured vibration was between the $\mathrm{X}$ and $\mathrm{Z}$ directions as defined by ISO; this is the direction associated with the highest vibration and was nearly the same as that adopted by the rider's forearms during the riding of this motorcycle. In addition, when the motorcycle was test-run on asphalt with the wheel conditions given in table 1 , the vibration in the $\mathrm{X}$ direction was also measured, because there were occasions when the maximum vibration occurred in the $\mathrm{X}$ direction. The directions are shown in figure 1. The handgrips were held by the rider's hands while the motorcycle was operating at normal power.

The atmospheric temperature and the temperature and hardness of the snow required for obtaining the physical properties of snow were measured every 30 min during the work period. The snow hardness was tested with the Kinoshita tester (4), the pole head having a cone vertical angle of $45^{\circ}$.

\section{Results and discussion}

\section{Vibration acceleration}

Figures 2 and 3 show the results obtained from a onethird octave-band analysis of vibration acceleration when the motorcycle was running on the asphalted and unpaved roads with tires with normal treads.

The 4- to 8-h exposure guideline of ISO (3) (subsequently, referred to as the $\mathrm{A}$ line in this paper) is shown

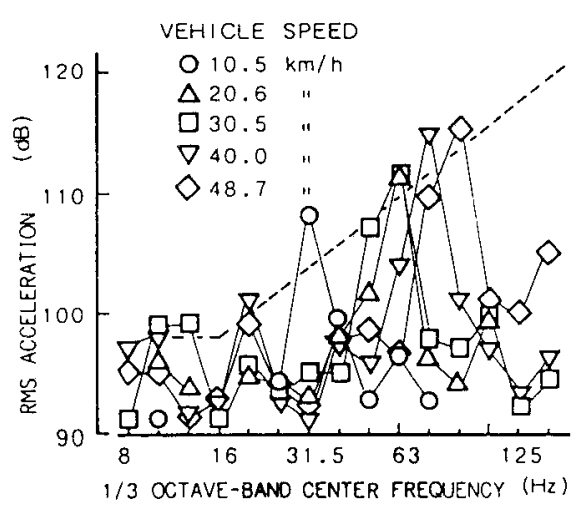

Figure 2. Components of the handlebar vibration in the arm direction on asphalted roads. (RMS $=$ root mean square) by a broken line in the figures $\left[A_{\text {ref }}=10^{-5} \mathrm{~m} / \mathrm{s}^{2}(\mathrm{ac}-\right.$ cording to Japanese industrial standard JIS C 5020), root-mean-square (RMS) value].

Asphalt road. The frequency $31.5 \mathrm{~Hz}$ showed the maximum acceleration level on asphalt when the speed was $10 \mathrm{~km} / \mathrm{h}$. At speeds of $20,30,40$, and $50 \mathrm{~km} / \mathrm{h}$,

Table 1. Pairs of front and rear tires used in tests with packed snow as the road surface.

\begin{tabular}{cll}
\hline Test & Front wheel & Rear wheel \\
\hline 1 & Snow & Studded snow \\
2 & Snow & Snow \& chain \\
3 & Snow & Snow \\
4 & Normal & Studded snow \\
5 & Studded snow & Studded snow \\
\hline
\end{tabular}

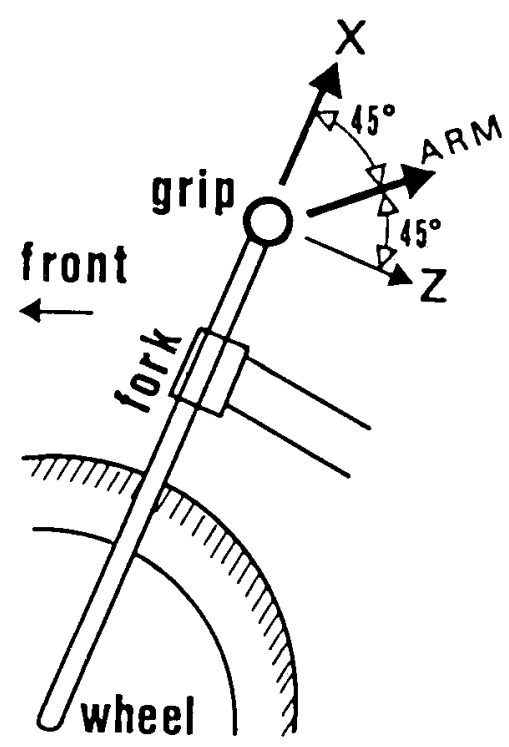

Figure 1. Directions of the measured vibration.

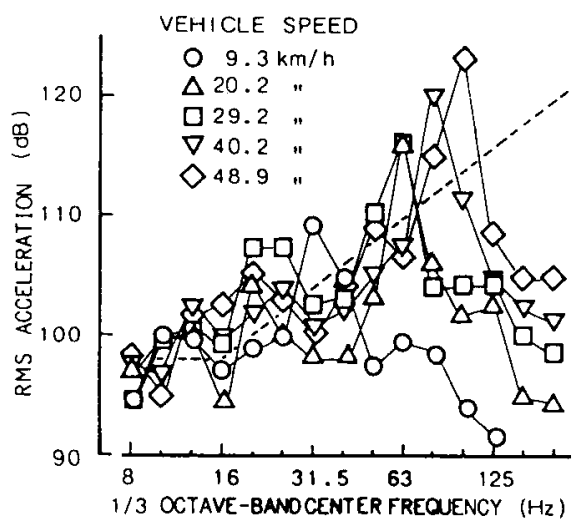

Figure 3. Components of the handlebar vibration in the arm direction on unpaved roads. (RMS = root mean square) 


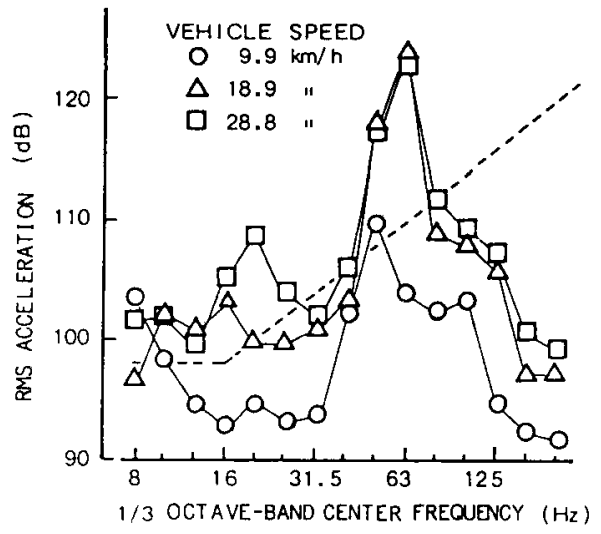

Figure 4. Components of the handlebar vibration in the arm direction on packed snow, test 1 (atmospheric temperature $-2.7^{\circ} \mathrm{C}$, snow temperature $-1.5^{\circ} \mathrm{C}$, snow hardness $3.2 \mathrm{kPa}$ ). (RMS $=$ root mean square)

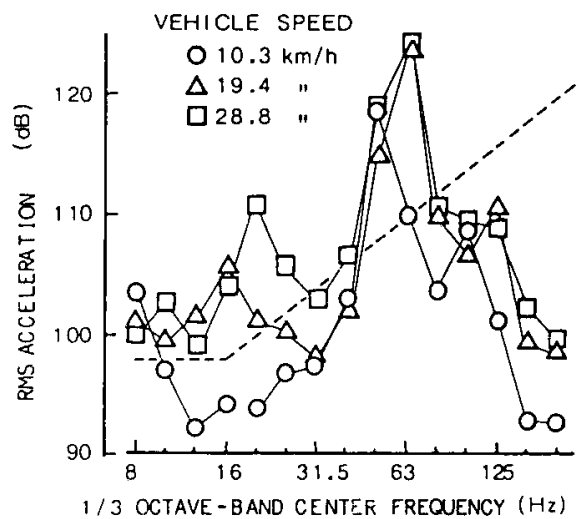

Figure 6. Components of the handlebar vibration in the arm direction on packed snow, test 3 (atmospheric temperature $-2.5^{\circ} \mathrm{C}$, snow temperature $-0.9^{\circ} \mathrm{C}$, snow hardness $6.2 \mathrm{kPa}$ ). (RMS $=$ root mean square)

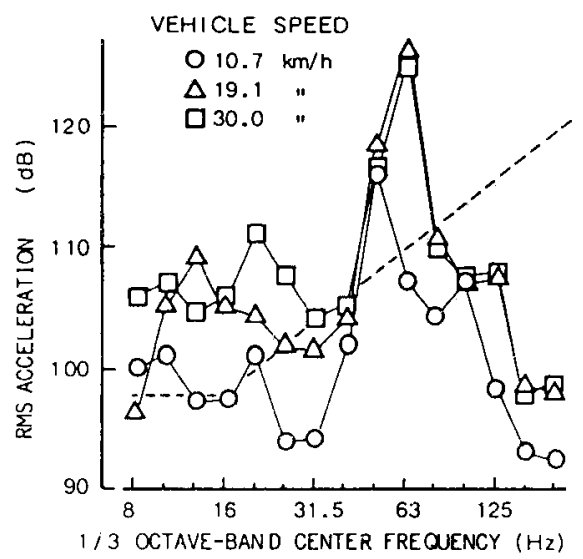

Figure 8. Components of the handlebar vibration in the arm direction on packed snow, test 5 (atmospheric temperature $-4.0^{\circ} \mathrm{C}$, snow temperature $-2.0^{\circ} \mathrm{C}$, snow hardness $4.6 \mathrm{kPa}$ ). (RMS = root mean square)

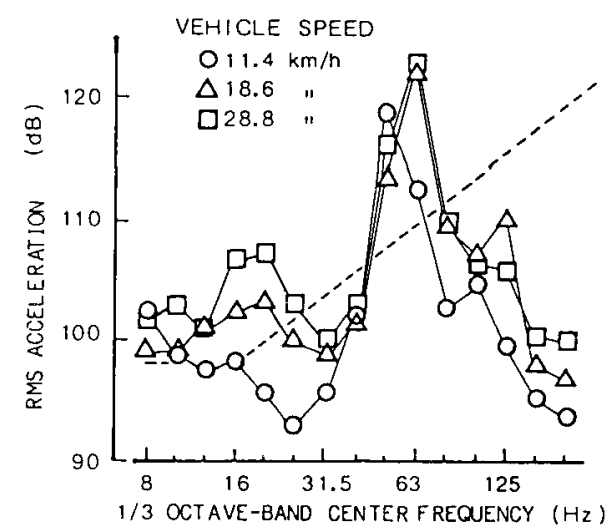

Figure 5. Components of the handlebar vibration in the arm direction on packed snow, test 2 (atmospheric temperature $-1.3^{\circ} \mathrm{C}$, snow temperature $-1.8^{\circ} \mathrm{C}$, snow hardness $7.2 \mathrm{kPa}$ ). (RMS $=$ root mean square)

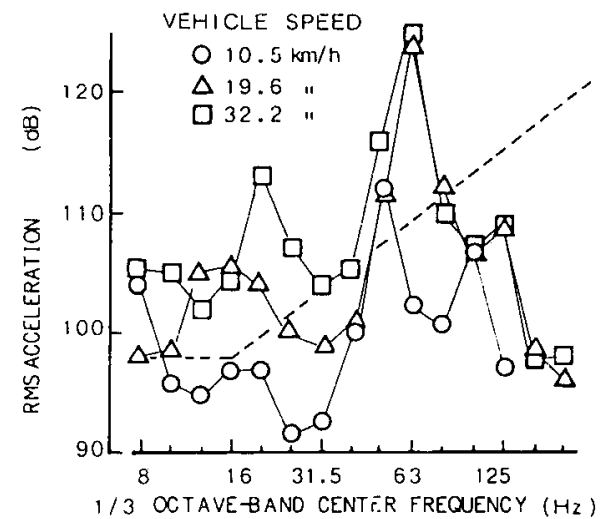

Figure 7. Components of the handlebar vibration in the arm direction on packed snow, test 4 (atmospheric temperature $-5.8^{\circ} \mathrm{C}$, snow temperature $-2.4^{\circ} \mathrm{C}$, snow hardness $5.8 \mathrm{kPa}$ ). (RMS $=$ root mean square)

the frequencies associated with the maximum acceleration were 63,80 , and $100 \mathrm{~Hz}$, respectively. These frequencies corresponded to that of the engine speed in each test run and the levels all exceeded the A line.

In the lower frequency regions, below $25 \mathrm{~Hz}$, the significant levels at $18 \mathrm{~Hz}$ and near $10 \mathrm{~Hz}$ seemed to be associated with the fundamental and second harmonic of the natural frequency of the unsprung mass containing the wheel when the speed was above 20 $\mathrm{km} / \mathrm{h}$. Even in the lower frequency regions of less than $25 \mathrm{~Hz}$, the A line was exceeded.

Unpaved road. The frequency associated with the maximum acceleration level on unpaved road again corresponded to that of the engine speed in the same manner as occurred on asphalt roads. These frequencies were $31.5 \mathrm{~Hz}$ at $10 \mathrm{~km} / \mathrm{h}, 63 \mathrm{~Hz}$ at $20 \mathrm{~km} / \mathrm{h}$ and 
Table 2. Regions of frequency exceeding the exposure guideline while the motorcycle was in operation on asphait under the same wheel conditions as those used on packed snow. (In the arm direction)

\begin{tabular}{|c|c|c|c|c|c|c|c|c|}
\hline \multirow{2}{*}{ Test } & \multicolumn{4}{|c|}{ Low frequency $(<25 \mathrm{~Hz})$} & \multicolumn{4}{|c|}{ High frequency $(>25 \mathrm{~Hz})$} \\
\hline & $10 \mathrm{~km} / \mathrm{h}$ & $20 \mathrm{~km} / \mathrm{h}$ & $30 \mathrm{~km} / \mathrm{h}$ & $40 \mathrm{~km} / \mathrm{h}$ & $10 \mathrm{~km} / \mathrm{h}$ & $20 \mathrm{~km} / \mathrm{h}$ & $30 \mathrm{~km} / \mathrm{h}$ & $40 \mathrm{~km} / \mathrm{h}$ \\
\hline 1 & - & - & 10 & $10-12.5$ & $50-63$ & 50,100 & 80 & 100 \\
\hline 3 & - & 10 & 10 & $10-12.5$ & $50-63$ & $50-63$ & 80 & 100 \\
\hline 4 & - & - & 10 & 10 & $50-63$ & 80 & 80 & 100 \\
\hline 5 & - & 10 & $10-12.5$ & $10-20$ & $40-50$ & $80-100$ & 80 & 125 \\
\hline
\end{tabular}

$30 \mathrm{~km} / \mathrm{h}, 80 \mathrm{~Hz}$ at $40 \mathrm{~km} / \mathrm{h}$, and $100 \mathrm{~Hz}$ at $50 \mathrm{~km} / \mathrm{h}$. They all exceeded the A line. At $50 \mathrm{~km} / \mathrm{h}$, a peak of $50 \mathrm{~Hz}$ occurred that was associated with one-half the engine speed. It also exceeded the A line.

As on the asphalt road, the significant levels occurred at frequencies near $12.5 \mathrm{~Hz}(10 \mathrm{~Hz}$ at $10 \mathrm{~km} / \mathrm{h})$. They all exceeded the A line. Thus, the vibration of the unsprung mass was increased due to the effect of the roughness of the road surface, and the levels of the lower frequency vibration increased accordingly.

Packed-snow surface. The frequency components that are shown in figures 4 to 8 relate to measurements made during operation on packed snow under the wheel conditions described in table 1. It is apparent that the major factor causing the handlebars to vibrate is the engine of the motorcycle. The same effect occurred on the asphalt and the unpaved road because the maximum vibration level was in the frequency band associated with the engine speed, irrespective of the different wheel conditions.

At $20 \mathrm{~km} / \mathrm{h}$ and $30 \mathrm{~km} / \mathrm{h}$, the levels exceeded the A line by between about 12 and $16 \mathrm{~dB}$. At $10 \mathrm{~km} / \mathrm{h}$, the maximum levels exceeded the $A$ line, but the differences were dependent upon the wheel conditions.

In this test, it was found that there were some significant peaks in the acceleration level in the lower frequency region below $25 \mathrm{~Hz}$. The excess over the A line was between about 9 and $13 \mathrm{~dB}$. These peaks were caused, as was the case with the normal tires, by the vibration of the unsprung mass containing the wheels. They occurred as a result of the fundamental vibration of the unsprung mass at 10 and $20 \mathrm{~km} / \mathrm{h}$, and as a result of the fundamental and the second harmonic at $30 \mathrm{~km} / \mathrm{h}$.

Asphalt road under the same wheels conditions as on the snow-packed surface. Table 2 shows the frequency region in which the magnitude of vibration measured in the arm direction for each test, apart from test 2, exceeded the A line.

Once again, the frequencies at which the maximum levels occurred corresponded with that of the engine running speed. All these levels were lower than those measured during the operation of the motorcycle on packed snow at speeds above $20 \mathrm{~km} / \mathrm{h}$, except at 40 $\mathrm{km} / \mathrm{h}$ in test 5 . However, they all exceeded the A line. At frequencies of less than $25 \mathrm{~Hz}$ the acceleration levels were lower than those measured on the packed snow,

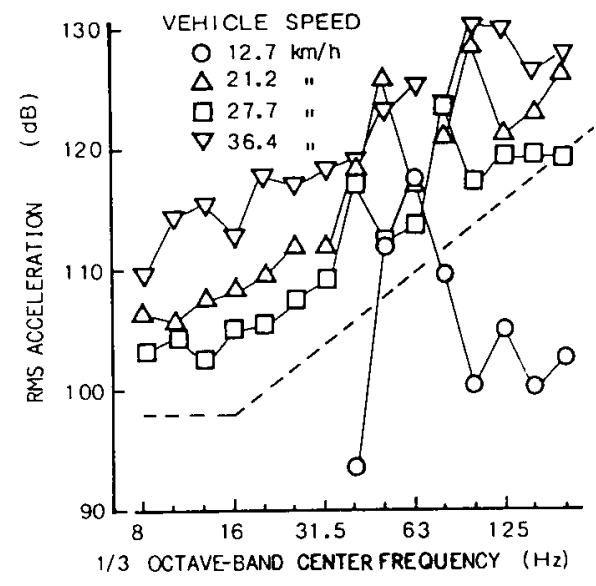

Figure 9. Components of the handlebar vibration in the $X$ direction on asphalted road under the same conditions as on packed snow in test 1 (figure 4). (RMS $=$ root mean square)

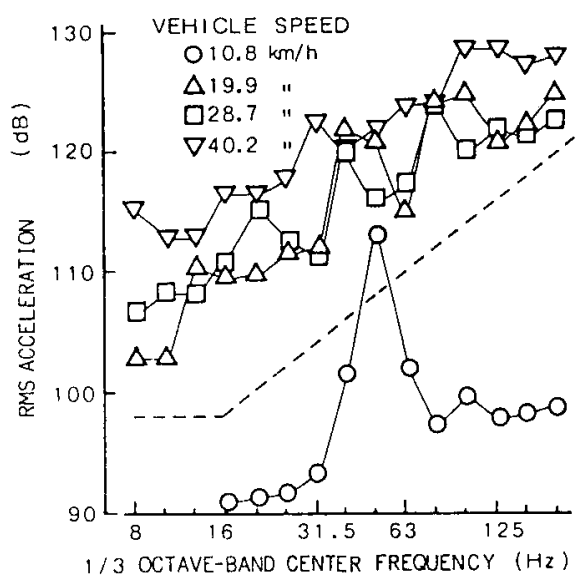

Figure 10. Components of the handlebar vibration in the $X$ direction on asphalted road under the same conditions as on packed snow in test 5 (figure 8 ). (RMS = root mean square)

and the frequency region over which the $\mathrm{A}$ line was exceeded became narrower.

Examples of the frequency analysis in the $\mathrm{X}$ direction are shown for test 1 in figure 9 and for test 5 in figure 10 . The frequency regions at which the acceleration levels exceeded the A line are shown in table 3 . 
Table 3. Regions of frequency exceeding the exposure guideline while the motorcycle was in operation on asphalt under the same wheel conditions as those used on packed snow. (In the $X$ direction)

\begin{tabular}{|c|c|c|c|c|c|c|c|c|}
\hline \multirow{2}{*}{ Test } & \multicolumn{4}{|c|}{ Low frequency $(<25 \mathrm{~Hz})$} & \multicolumn{4}{|c|}{ High frequency $(>25 \mathrm{~Hz})$} \\
\hline & $10 \mathrm{~km} / \mathrm{h}$ & $20 \mathrm{~km} / \mathrm{h}$ & $30 \mathrm{~km} / \mathrm{h}$ & $40 \mathrm{~km} / \mathrm{h}$ & $10 \mathrm{~km} / \mathrm{h}$ & $20 \mathrm{~km} / \mathrm{h}$ & $30 \mathrm{~km} / \mathrm{h}$ & $40 \mathrm{~km} / \mathrm{h}$ \\
\hline $\begin{array}{l}1 \\
3 \\
4 \\
5\end{array}$ & $\begin{array}{l}\overline{-} \\
\overline{-}\end{array}$ & $\frac{\overrightarrow{A l l}}{\overrightarrow{A l l}}$ & $\begin{array}{l}\text { All } \\
\text { All } \\
\text { All } \\
\text { All }\end{array}$ & $\begin{array}{l}\text { All } \\
\text { All } \\
\text { All } \\
\text { All }\end{array}$ & $\begin{array}{c}50-63 \\
50-63 \\
50-63 \\
50\end{array}$ & $\begin{array}{c}\text { All } \\
63 \\
40,80 \\
\text { All }\end{array}$ & $\begin{array}{c}\text { All } \\
40-125 \\
40-125 \\
\text { All }\end{array}$ & $\begin{array}{l}\text { All } \\
\text { All } \\
\text { All } \\
\text { All }\end{array}$ \\
\hline
\end{tabular}

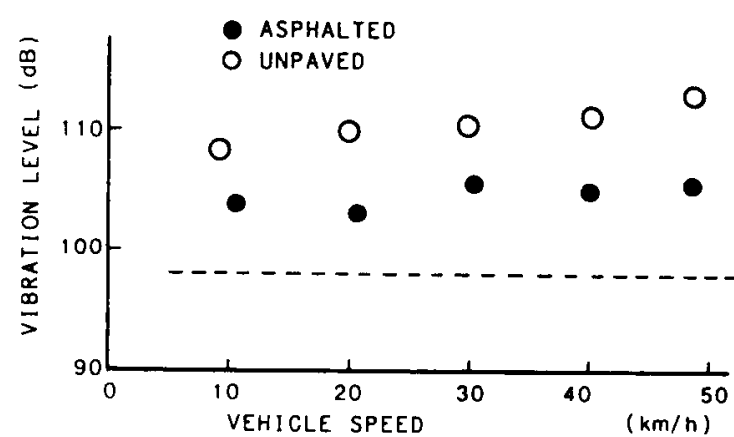

Figure 11. Vibration levels in the arm direction on asphalted and unpaved roads.

The frequencies at which the acceleration is at a maximum level were the same as those measured in the arm direction. These levels exceeded the A line but were higher than those obtained in the packed-snow tests. The peak levels were found in one-half of the frequency showing the maximum level under all the conditions at 30 and $40 \mathrm{~km} / \mathrm{h}$, and at $20 \mathrm{~km} / \mathrm{h}$ except in test 3.

At less than $25 \mathrm{~Hz}$, the levels exceeded the A line at $20 \mathrm{~km} / \mathrm{h}$ at all frequencies in tests 1 and 5 and at between 12.5 and $20 \mathrm{~Hz}$ in test 4 , and at all frequencies at speeds above $30 \mathrm{~km} / \mathrm{h}$. The levels at $10 \mathrm{~km} / \mathrm{h}$ were lower and under the $\mathrm{A}$ line.

\section{Vibration level}

The vibration levels (3) obtained by the weighting of the vibration acceleration levels are shown for the measurements on asphalt and the unpavad road with normal tires in figure 11, and in figure 12 for measurements on the packed snow. In figure 13 the levels in the arm and the $X$ directions are shown for the asphalted roads under the same conditions as were used on the packed snow. The 4- to 8-h weighted exposure level of ISO is represented by a broken line. There was a tendency for the vibration level to increase with the vehicle speed when normal tires were in use on the asphalt and the unpaved road. All the vibration levels exceeded the weighted exposure level.

On the packed snow, the levels were higher than those recorded on the asphalt and the unpaved road,

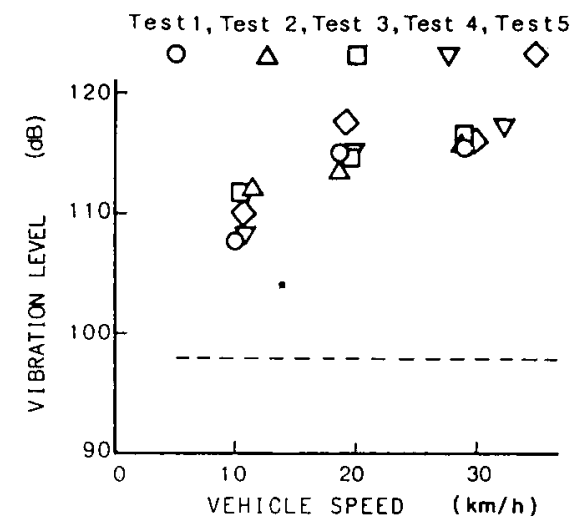

Figure 12. Vibration levels in the arm direction on packed snow.

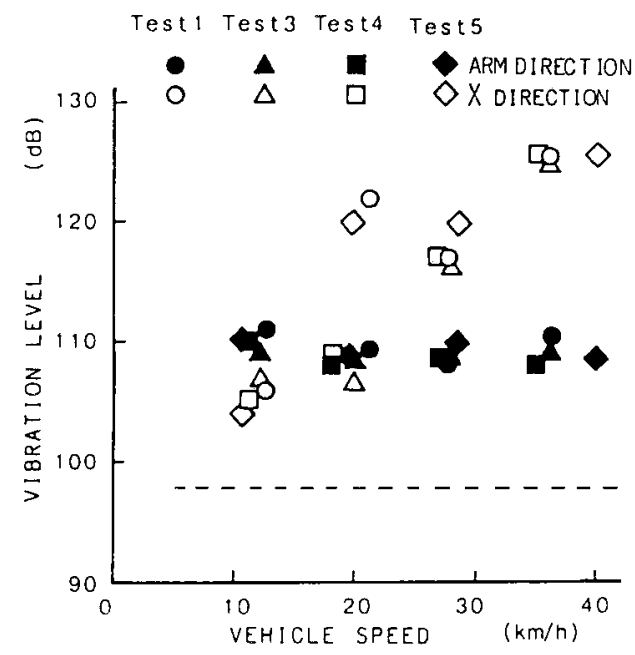

Figure 13. Vibration levels in the arm direction and in the $X$ direction on asphalted road under the same wheel conditions as on packed snow.

and they were also higher at 20 and $30 \mathrm{~km} / \mathrm{h}$ than at $10 \mathrm{~km} / \mathrm{h}$. When the motorcycle was operated on asphalt under the same wheel conditions as on the packed snow, the vibration levels measured in the arm direction did not vary much with differences in the speed and wheel conditions. The vibration levels in the $\mathrm{X}$ direction were higher at speeds of $20 \mathrm{~km} / \mathrm{h}$ and above (except at $20 \mathrm{~km} / \mathrm{h}$ in tests 3 and 4 ) than in the arm 
direction. The corresponding levels in the $\mathrm{X}$ direction at $10 \mathrm{~km} / \mathrm{h}$ were lower than in the arm direction. All these levels exceeded the recommended weighted exposure level.

\section{Conclusions}

The results of our study can be summarized as follows:

1. On all the tested road surfaces, the maximum level of the vibration acceleration occurred at the same frequency as one-half the frequency of the speed of the running engine. This occurrence indicates that the vibration at the handlebars of the motorcycle is mainly caused by the engine. All the maximum levels measured exceeded the 4- to 8-h exposure guideline of ISO.

2. The direction in which the maximum vibration acceleration on the asphalted, the unpaved, and the packed-snow roads occurred corresponded to that of the rider's arm direction. It was at a $45^{\circ}$ angle below the $\mathrm{X}$ direction of the ISO standard and was directed towards the rider. When the motorcycle was operated on asphalt under the same wheel conditions as on packed snow, the maximum level occurred in the $\mathrm{X}$ direction at speeds of $20 \mathrm{~km} / \mathrm{h}$ or more.

3. The effects of the vibration of the unsprung mass, which includes the front wheel, are apparent in the frequency range below $25 \mathrm{~Hz}$. The vibration acceleration levels and the peak levels measured in this frequency range exceeded the 4 - to 8 -h weighted exposure level of ISO, apart from the level measured at speeds of 10 $\mathrm{km} / \mathrm{h}$ on asphalt with the use of normal tires and at $10 \mathrm{~km} / \mathrm{h}$ on asphalt under the same wheel conditions as on the packed snow ( $<20 \mathrm{~km} / \mathrm{h}$ in test 3 ).
4. The vibration levels measured exceeded the 4- to 8-h weighted exposure level of ISO under all the measurement conditions.

\section{Acknowledgments}

The authors wish to thank Professor S Yamada of the Department of Public Health, Nagoya University, for his advice with these studies and the students of the Meijo University, who helped with this experiment.

\section{References}

1. Bentley S, O'Connor DE, Load P, Edmonds OP. Vibration white finger in motorcycle speedway riders. In: Brammer AJ, Taylor W, ed. Vibration effects on the hand and arm in industry. John Wiley \& Sons, New York, NY 1982, pp 189-192.

2. Harrison RT, Murphy WA. Motorcycle handlebar vibration. In: Brammer AJ, Taylor W, ed. Vibration effects on the hand and arm in industry. John Wiley \& Sons, New York, NY 1982, pp 239-244.

3. International Organization for Standardization. Guidelines for the measurement and assessment of human exposure to hand-transmitted vibration. Draft international standard. Geneva 1979. (ISO/DIS 5349).

4. Japanese Society of Snow and Ice. A manual of measurement of snow cover. Jpn J Res Snow Ice (1970): 4, 19-22.

5. Matsumoto T, Yokomori M, Harada N, Fukuchi Y, Kanamori M, Gotoh M. Mailmen's vibration hazards induced by motorcycle riding - Results of cooling load tests. Ind Health 20 (1982) 167-175.

6. Takamatsu M, Futatsuka M, Sakurai T, and 23 other persons. A study of the extent and scope of local vibration hazards in Japan. Ind Health 20 (1982) 177-190.

7. Tominaga Y. Handle grip vibration of postal delivery motorbikes. Jpn J Sci Labour 57 (1981): 7, 295-305.

8. Yokomori $M$, Yamada S, Nakagawa T, Matsumoto $T$. The vibration of the handlebars of a motorcycle in running on the paved road. Jpn J Ind Health 23 (1981): 2, $134-140$. 